\title{
Cluster observations of a structured magnetospheric cusp
}

\author{
N. Balan ${ }^{1}$, H. Alleyne ${ }^{1}$, S. Walker ${ }^{1}$, H. Réme ${ }^{2}$, P. M. E. Décréau ${ }^{3}$, A. Balogh ${ }^{4}$, M. André ${ }^{5}$, A. N. Fazakerley ${ }^{6}$, \\ N. Cornilleau-Wehrlin ${ }^{7}$, D. Gurnett ${ }^{8}$, and M. Fraenz ${ }^{9}$ \\ ${ }^{1}$ Automatic Control and Systems Engineering, University of Sheffield, Sheffield, UK \\ ${ }^{2}$ CESR, Toulouse, France \\ ${ }^{3}$ LPCE/CNRS and Universite d'Orleans, France \\ ${ }^{4}$ Blackett Laboratory, Imperial College, London, UK \\ ${ }^{5}$ SISP, Uppsala, Sweden \\ ${ }^{6}$ Mullard Space Science Lab, Uni. College London, UK \\ ${ }^{7}$ CETP-IPSL/CNRS, Vélizy, France \\ ${ }^{8}$ University of Iowa, Iowa, USA \\ ${ }^{9}$ MPI für Sonnen Systemforschung, Lindau, Germany
}

Received: 27 January 2006 - Revised: 10 March 2006 - Accepted: 16 March 2006 - Published: 19 May 2006

\begin{abstract}
On 18 April 2002 the Cluster spacecraft crossed through the northern outer magnetospheric cusp region during 16:25-17:55 UT when the solar wind dynamic pressure was rather low $(<2 \mathrm{nPa})$ and IMF $B_{z}$ was more negative than IMF $B_{y}$. The Cluster data from the FGM, CIS, PEACE, EFW, WHISPER and STAFF instruments reveal that the cusp is structured with three anti-sunward ion flow events of durations $\approx 1.5,17.5$ and $19.0 \mathrm{~min}$, with bulk plasma flow roughly parallel to the magnetopause toward north. The ion and electron densities within the events are much greater than those outside. The zonal electric field in the ion flow events turns eastward as expected from $\boldsymbol{V} \times \boldsymbol{B}$ effect. The sharp inward boundaries of the ion flow events cross the four spacecraft in one time sequence, and the outward boundaries of the events cross the spacecraft in the reverse time sequence. The observations studied using magnetosphere and magnetopause models suggest that the structured cusp is a temporal feature that arises due to three inward and outward movements of the magnetopause by about $1.5 R_{E}$ so that Cluster, while crossing through the cusp, happened to be in the magnetosheath (ion flow event) and cusp alternately. The magnetopause moved due to the changes in the solar wind dynamic pressure by up to $100 \%$.
\end{abstract}

Keywords. Magnetospheric physics (Magnetopause, cusp and boundary layers; Magnetosheath; Solar windmagnetosphere interactions)

Correspondence to: N. Balan

(b.nanan@sheffield.ac.uk)

\section{Introduction}

The magnetospheric cusps, originally proposed as magnetic null points (Chapman and Ferraro, 1930), represent topological boundaries separating the dayside field lines from those extending into the nightside tail lobes. The topological boundaries (or cusps) are observed as longitudinally extended funnel shaped regions in the high latitude dayside magnetosphere, one in each hemisphere, through which solar wind mass and energy can directly enter the magnetosphere and find their way down to the ionosphere without crossing the geomagnetic field lines; there can also be a small reverse flow from the ionosphere to the nightside magnetosphere. The regions sunward and anti-sunward of the cusp openings are termed entry layer (EL) and plasma mantle (PM) (Haerendel et al., 1978). The cusps are also known as favourable regions to observe the signatures of magnetic reconnection between the interplanetary magnetic field and magnetosphere (Dungey, 1961). The mechanisms that populate the cusps and surrounding regions are known to involve magnetic reconnection (Lockwood and Smith, 1992; Onsager et al., 2001) and associated flux transfer events (FTEs) (Russell and Elphic, 1979), precipitation of solar wind plasma through the reconnected field lines as they convect toward nightside, plasma turbulence at magnetospheric boundaries, Kelvin-Helmholtz vortices and plasma diffusion, (Haerendel, 1978; Haerendel et al., 1978; Yamauchi et al., 2003; Hasegawa et al., 2004).

The cusp-like regions, though centred at around $80^{\circ}$ invariant latitude at magnetic noon at a geocentric distance of $8 R_{E}$, are found to extend to about $70^{\circ}$ invariant latitudes,

Published by Copernicus GmbH on behalf of the European Geosciences Union. 
07:00 to 17:00 MLT (magnetic local times), and 6 to $9 R_{E}$ geocentric distances (Stubbs et al., 2004). The high altitude region of the cusp is usually termed outer cusp (e.g. Savin et al., 2004). Between the cusp and magnetosheath there is an intermediate region called the exterior cusp, which is bounded on the Earthward side by the cusp-like indentation of the magnetopause and externally by the free-flow stream line of the magnetosheath flow (Spreiter et al., 1967; Sckopke et al., 1976). The exterior cusp, like the cusp proper, is generally associated with depressed magnetic field and lies predominantly within 10:00-13:00 MLT and extends to both earlier and later MLTs (Lavraud et al., 2004; Zhang et al., 2005).

Prior to the Cluster mission, the cusps and surrounding regions have been studied using ground-based and satellite observations, for reviews see Smith and Lockwood (1996), Russell (2000) and Fritz et al. (2003). Using the data from the ISIS and VELA 4B satellites, Heikkila and Winningham (1971) have shown that plasma at different altitudes within the cusp have similar characteristics. The shape, size, location and populating mechanisms of the Cusps have also been revealed using the data from other satellites such as HEOS, Hawkeye, Interball and POLAR (Hedgecock and Thomas, 1975; Haerendel et al., 1978; Farrell and Van Allen, 1990; Zelenyi et al., 1997; Chen et al., 1997; Russell, 2000; Dunlop et al., 2000; Merka et al., 2000; Wing et al., 2001; Sandahl, 2002).

The Cluster mission (Escoubet et al., 2001), consisting of four satellites in a polar elliptical orbit of $4 \times 19.6 R_{E}$, inclination of $90^{\circ}$ and orbital period of $\approx 58 \mathrm{~h}$, has the main scientific objective of studying small-scale structures and macroscopic turbulence in three dimensions that arise in key plasma regions in the magnetosphere, bow shock and solar wind. The data from the 11 instruments onboard the Cluster satellites independently and together with other satellites and ground-based instruments have provided better understanding of the 3D structure, dynamics and populating mechanisms of the cusps under southward and northward IMF conditions. The data have also revealed the existence of a double cusp structure, and field-aligned currents and plasma instabilities in the cusp (e.g. Bosqued et al., 2001; Krauklis et al., 2001; Gurnett et al., 2001; Taylor et al., 2001; Decreau et al., 2001; Opgenoorth et al., 2001; Pitout et al., 2001; Réme et al., 2001; Cornilleau et al., 2003). Recently, Cargill et al. (2005) presented a review of Cluster at the magnetospheric cusps.

The present paper reports the structures observed in the northern outer magnetospheric cusp crossed by Cluster during 16:25-17:55 UT on 18 April 2002. At this time a geomagnetic storm was in progress (Dst $\approx-100 \mathrm{nT}$ and $\mathrm{Kp}=5$ ), solar wind dynamic pressure was rather low, and IMF $B_{z}$ was more negative than IMF $B_{y}$. The data from the FGM, CIS, PEACE, EFW, STAFF and WHISPER instruments reveal that the outer cusp is structured with three anti-sunward ion flow events. The structured cusp is interpreted as alter- nate regions of cusp and magnetosheath, which happened due to the inward and outward movements of the magnetopause with respect to Cluster caused by the changes in the solar wind dynamic pressure. The results are presented and discussed using magnetosphere and magnetopause models (Tsyganenko and Stern, 1996; Shue et al., 1998) and orbit visualization tool of the OVT team (2002) (http://ovt.irfu.se/, 2002 ) in Sect. 3. Section 4 contains a summary. Zong et al. (2004) presented the RAPID data during this cusp event.

\section{Data and IMF conditions}

The data used for the study include the ion density, ion velocity, ion temperature and ion energy-flux spectrum measured by CIS (Composition Ion Spectrometer) (Réme et al., 2001), electron energy-flux spectrum measured by PEACE (Plasma Electron And Current Experiment) (Johnstone et al., 1997), magnetic field measured by FGM (Flux Gate Magnetometer) (Balogh et al., 2001) and electric field measured by EFW (Electric Fields and Waves) (Gustafsson et al., 2001). The data from the WHISPER (Waves of HIgh frequency and Sounder for Probing Electron Density by Relaxation) and STAFF (Spatio Temporal Analysis of Field Fluctuation) instruments are also used for the electron density, and electric and magnetic waves (Decreau et al., 2001; CornilleauWehrlin et al., 2003). The CIS data are from the HIA (Hot Ion Analyser) instrument that measures the 3-D distribution function of the ions in the energy range from $\approx 5 \mathrm{eV} / \mathrm{e}$ to $32 \mathrm{keV} / \mathrm{e}$ without mass selection but with a good angular resolution (Réme et al., 2001). The ion density data from the CODIF (Composition and Distribution Function Analyser) CIS instrument is found to have problems during the cusp crossing, and HIA/CIS data are available only from SC1 and SC3. The Cluster data are in GSE coordinate system and have a time resolution of four seconds. The solar wind and IMF conditions are assessed using ACE (Advanced Composition Explorer) data (Skoug et al., 2004). The study also uses the magnetosphere model of Tsyganenko and Stern (1996), magnetopause model of Shue et al. (1998) and orbit visualization tool (http://ovt.irfu.se/, 2002.).

Figure 1 shows the satellite orbit projected on to the $\mathrm{X}-\mathrm{Z}$ plane that contains part of a model magnetosphere (Tsyganenko and Stern, 1989; OVT, 2002) at 17:00 UT on 18 April, obtained with appropriate input parameters $(\mathrm{Dst}=-100 \mathrm{nT}$ and $\mathrm{Kp}=5$; solar wind pressure $=1.5 \mathrm{nPa}$ and velocity $=460 \mathrm{~km} \mathrm{~s}^{-1}$; IMF $B_{x}=4 \mathrm{nT}, B_{y}=-8 \mathrm{nT}$ and $B_{z}=-8 \mathrm{nT}$ ). As shown, the orbit during 16:25-17:55 UT passed through the northern outer cusp. The orbit coordinates during the cusp crossing range from $\mathrm{X}=6.67 R_{E}$, $\mathrm{Y}=-2.5 R_{E}$ and $\mathrm{Z}=8.22 R_{E}$ to $\mathrm{X}=8.02 R_{E}, \mathrm{Y}=-3.98 R_{E}$ and $\mathrm{Z}=8.19 R_{E}$. The satellite configuration, expanded many times in Fig. 1, is tetrahedron with an intersatellite spacing of approximately $100 \mathrm{~km}$. The inset in Fig. 1 shows the orbit starting (at 18:32:23 UT) after the cusp crossing on 18 April. 


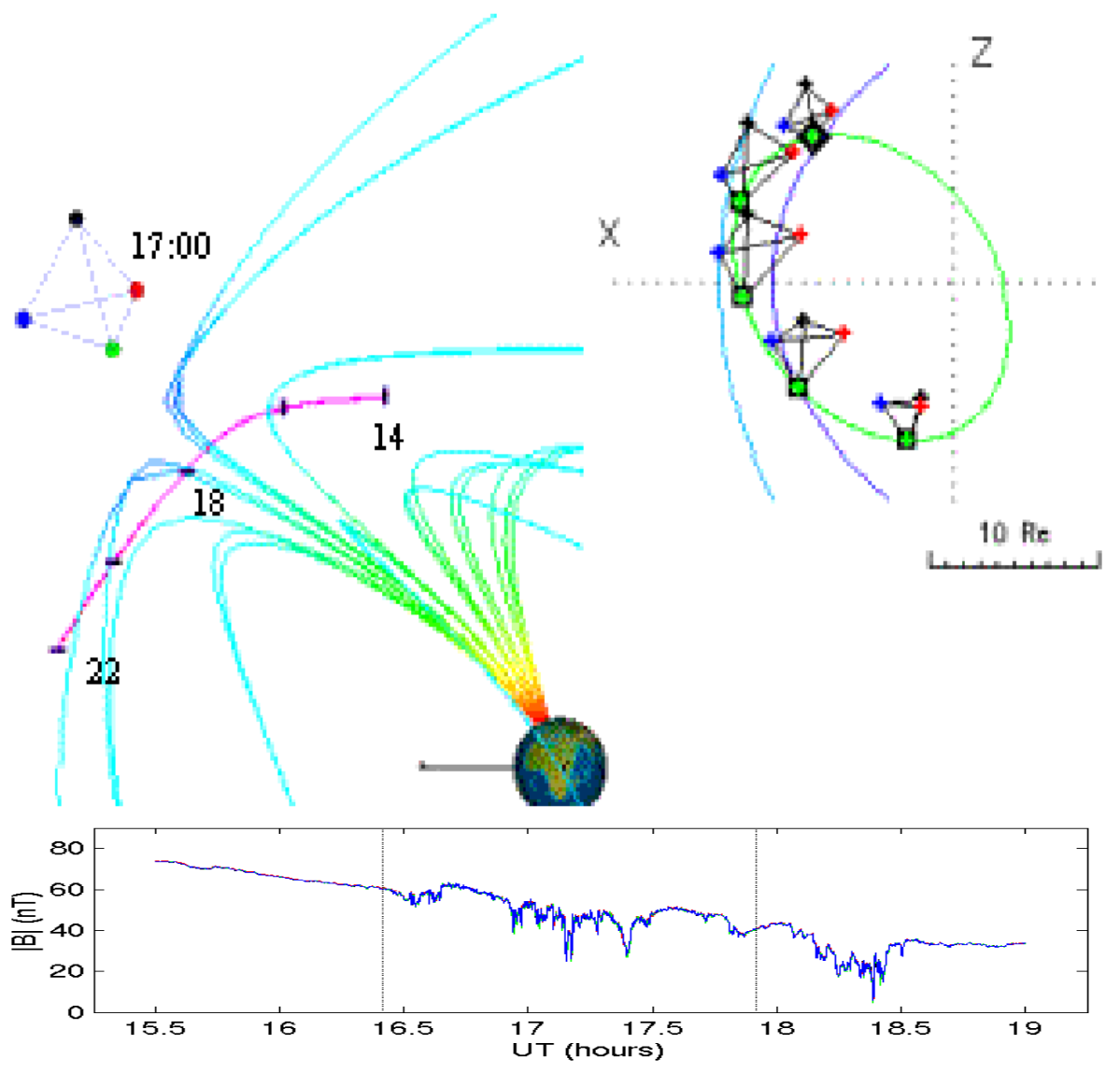

Fig. 1. Cluster orbit during 14:00-22:00 UT on 18 April 2002 projected onto the $X-Z$ plane that contains part of a model magnetosphere at 17:00 UT obtained from the T96 model with appropriate input parameters (IMF $B_{y}=-8 \mathrm{nT}$, IMF $B_{z}-8 \mathrm{nT}$, Dst=-100 nT, Kp=5 and solar wind pressure $=1.5 \mathrm{nPa}$ ). The cusp crossings occurred during 16:25-17:55 UT. The inset shows the orbit starting (at 18:32:23 UT) after the cusp crossing on 18 April. The satellite configuration (SC1 - black, SC2 - red, SC3 - green and SC4 - blue, expanded many times and shown for 17:00 UT) is tetrahedron during the crossing. The bottom panel shows the total magnetic field B measured by FGM on all 4 satellites during 15:30-19:00 UT; the period of the cusp crossing is marked between the vertical lines.

The bottom panel of Fig. 1 shows the total magnetic field measured by FGM during 15:30-19:00 UT. The field undergoes several depressions during the cusp crossing indicating the possibility of a structured cusp. The magnetic field also shows a large depression at around 18:20 UT, which, from the ion density data shown below, does not seem to be part of the cusp.

The prevailing solar wind and IMF conditions measured by ACE are shown in Fig. 2, with a time resolution of $64 \mathrm{~s}$ for the plasma data and $16 \mathrm{~s}$ for IMF; IMF is in GSM coordinates. As shown by the top panel, the ACE satellite, which was at the L1 point at about $225 R_{E}$ away from the Earth, measured an average wind speed of about $460 \mathrm{~km} \mathrm{~s}^{-1}$ (at around 15:30 UT). This implies a time delay of about $50 \mathrm{~min}$ for the solar wind to reach Cluster giving a relevant ACE period of 15:35-17:05 UT. During this period, the velocity undergoes small fluctuations of less than $2.5 \%\left(12 \mathrm{~km} \mathrm{~s}^{-1}\right)$. However, the solar wind density (around $3 \mathrm{~cm}^{-3}$, panel 2) undergoes up to $100 \%$ changes, which, in turn, cause corre- sponding changes in the solar wind dynamic pressure $\left(P_{d y n}\right)$ that fluctuates around one $\mathrm{nPa}$ (panel 3).

The magnetopause standoff distance (MP in $R_{E}$ ), calculated using the expression $\mathrm{MP}=11.3 R_{0}+0.25 B_{z}$ where $R_{0}=\left(P_{d y n} / 2\right)^{-1 / 6}$ with $P_{d y n}$ in $\mathrm{nPa}$ and $B_{z}$ in nT (Hultqvist et al., 1999), is also shown in Fig. 2 (panel 4). The distance fluctuates between 11 and $14 R_{E}$ during the period of interest. It may be noted that the density, pressure and standoff distance undergo two prominent increases a and c, and comparison with the Cluster data (shown in Fig. 4) indicates that another short-period increase $b$ might have also occurred at around 16:16 UT (when there is a gap in the ACE data). The solar wind azimuthal flow $\left(V_{y}\right)$ (panel 5) changed from about $10 \mathrm{~km} \mathrm{~s}^{-1}$ to $-45 \mathrm{~km} \mathrm{~s}^{-1}$ and remained at this level during 16:16-17:38 UT. As shown by panels 6-8 (Fig. 2), IMF $B_{x}$ is less than $4 \mathrm{nT}, B_{y}$ is between -5 and $-9 \mathrm{nT}$, and $B_{z}$ is between -8 and $-11 \mathrm{nT}$ during the period of interest, and $B_{y}$ and $B_{z}$ undergo small fluctuations at around 16:45 UT. Since IMF $B_{z}$ is southward, magnetic reconnection could occur in 

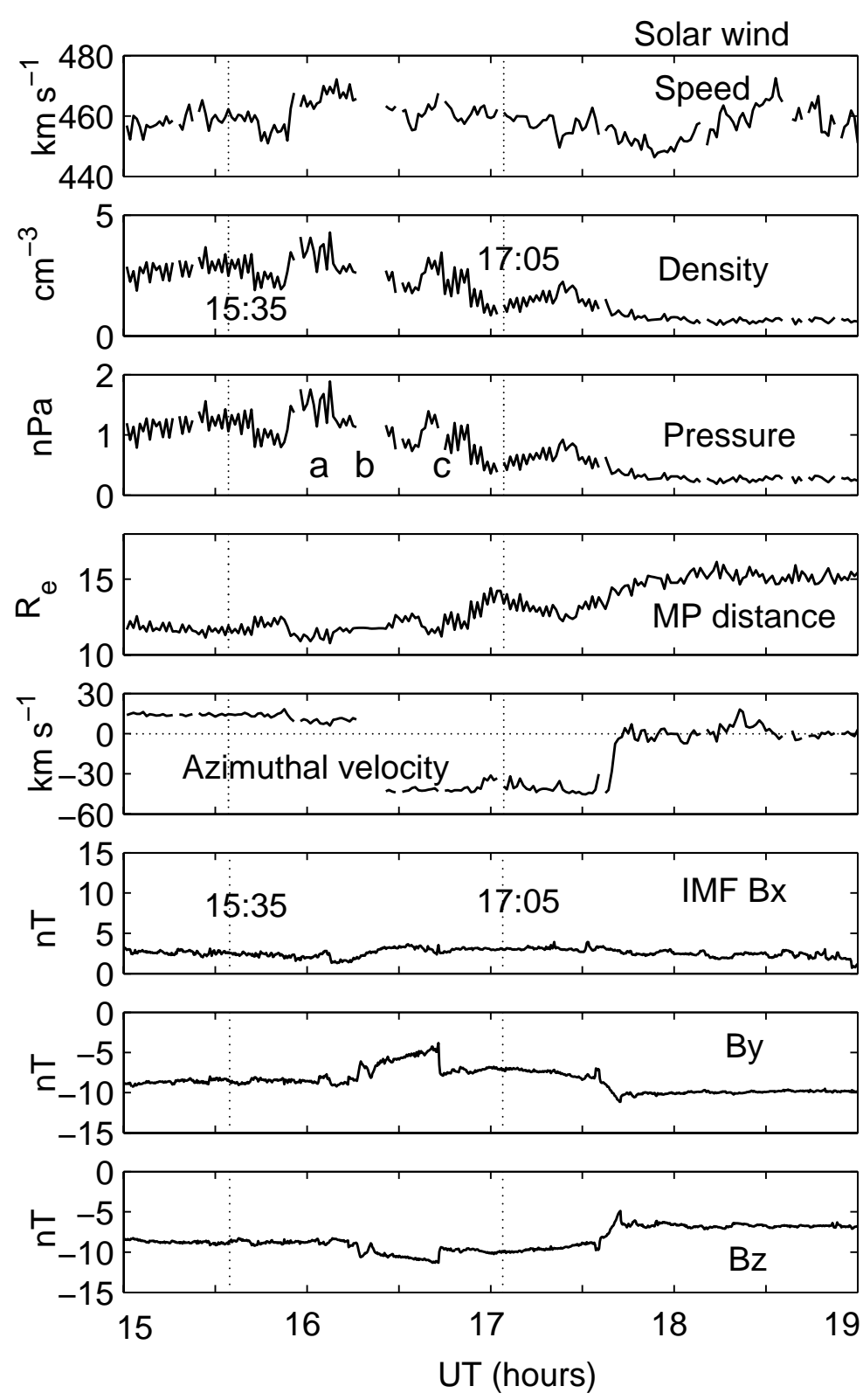

Fig. 2. The solar wind speed, density, dynamic pressure, magnetopause standoff distance and solar wind azimuthal velocity, and IMF $B_{x}$, $B_{y}$ and $B_{z}$ (in GSM) measured by the ACE satellite during 15:00-19:00 UT on 18 April 2002. The ACE time (15:35- 17:05) corresponding to the Cluster cusp crossing (16:25-17:55 UT) is shown between the vertical lines.

the dayside magnetopause and its effects propagate towards nightside (Lockwood and Smith, 1994; Onsager et al., 2001).

\section{Observations and discussion}

\subsection{Identification of cusp}

The plasma data provided by the CIS and PEACE instruments on spacecraft SC3 are displayed in Fig. 3 for the interval 15:00-20:00 UT. As shown, starting from the almost empty northern magnetospheric lobe, the spacecraft passes through the low-energy plasma mantle until about 16:25 UT. At around 16:25 UT there is a drop in total magnetic field (Fig. 1), increase in high energy ion $(>1 \mathrm{keV})$ and electron $(>0.2 \mathrm{keV})$ fluxes, and appearance of magnetosheath like $(100 \mathrm{eV})$ electron flux. This is identified as the satellite entry into the cusp as has been done earlier (Cargill et al., 2001; Bosqued et al., 2001). There is also a drop in low energy $(<10 \mathrm{eV})$ electron flux starting at around 16:25 UT. That, as discussed by Krauklis et al. (2001), is due to the secondary electrons from the satellite being discharged by the arrival of 


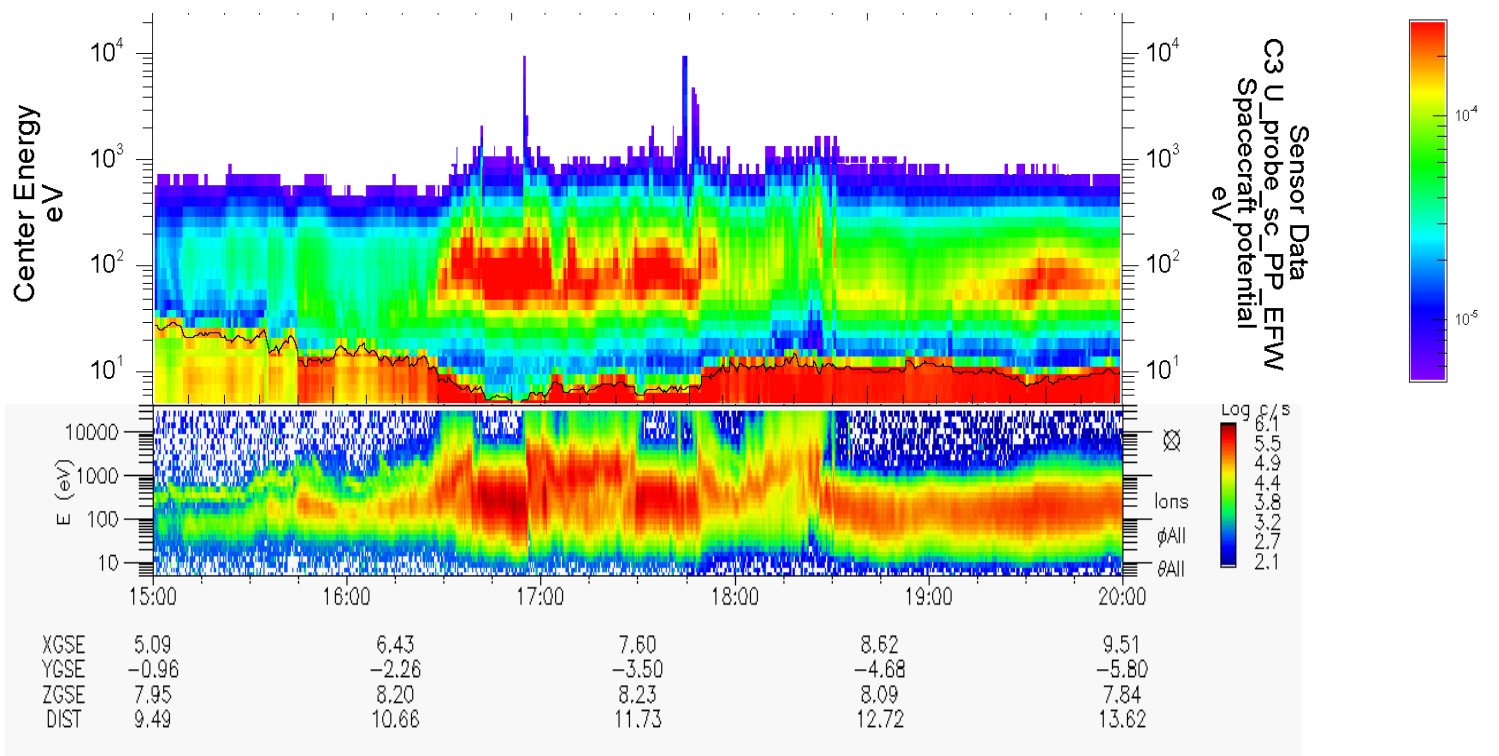

Fig. 3. The plasma data provided by PEACE and CIS instruments on Cluster SC3 during 15:00-20:00 UT on 18 April 2002. The cusp crossing occurred during 16:25-17:55 UT.

magnetosheath like ions, and is therefore a good indicator of the cusp. The satellite exits the cusp at around 17:55 UT, and enters the magnetosphere after passing through an accelerated plasma structure for about $30 \mathrm{~min}$, before entering the magnetosheath. But in what follows, we will concentrate on the time period 16:25-17:55 UT. As the satellite passes through the cusp region, it encounters structures in plasma, fields and waves, which are studied using single satellite and multi-satellite observations.

\subsection{Single-point Observations}

The velocity, density and temperature of the ions measured by the CIS instrument on SC3 during 15:50-19:00 UT are shown in Fig. 4 which also contains the solar wind dynamic pressure at the top, shifted by $50 \mathrm{~min}$ for easy comparison; the time interval between the vertical lines corresponds to the period of interest. As shown by the CIS data, the total ion velocity and its X-component (panel 2, red and black) are small in the plasma mantle (before the cusp). In the cusp region, the total velocity is high (average about $140 \mathrm{~km} \mathrm{~s}^{-1}$ ) and its X-component $V_{x}$ undergoes three distinct anti-sunward ion flow events $(\mathrm{a}, \mathrm{b}$ and $\mathrm{c}$ ) of duration $\approx 17.5 \mathrm{~min}, 1.5 \mathrm{~min}$ and $19.0 \mathrm{~min}$, with the velocity reaching up to $-110 \mathrm{~km} \mathrm{~s}^{-1}$. In between these events, the X-component of the velocity becomes very small. As shown by panel 3 (Fig. 4), the Y-component of the velocity ( $V_{y}$ in green) is westward and Z-component $\left(V_{z}\right.$ in blue) is northward in the anti-sunward ion flow events, and $V_{z}$ (up to $200 \mathrm{~km} \mathrm{~s}^{-1}$ ) is nearly twice as fast as $V_{x}$ and $V_{y}$, which are nearly equal. That indicates that the bulk plasma flow in the events is directed roughly parallel to the magnetopause surface.
The ion density in the cusp (panel 4, Fig. 4), is much greater than that outside. However, the density $\left(<10.0 \mathrm{~cm}^{-3}\right)$ is lower than average (Pitout et al., 2001). That may be because the crossing is through the outer cusp. The ion temperatures (bottom panel) are also high in the cusp region, rising up to $10 \mathrm{MK}$ compared to less than $3 \mathrm{MK}$ in the plasma mantle. The temperatures also exhibit anti-correlation with densities; that is, the temperatures are low in the anti-sunward ion flow events and high outside the events. That is consistent with the generally lower ion energy in the ion flow events compared to the regions outside the events (Fig. 3). The parallel and perpendicular temperatures (Fig. 4) exhibit strong temperature anisotropy, with the perpendicular temperature being nearly twice as high as the parallel temperature, compare the red and black curves in the bottom panel.

Though the event considered belong to a period of low solar wind dynamic pressure $(<2 \mathrm{nPa})$, there are significant variations (Figs. 2 and 4), and we will call hereafter the relatively higher values as "high"pressure. A comparison of the CIS data and solar wind data (Fig. 4) indicates that the antisunward ion flow events $\mathrm{a}, \mathrm{b}$ and $\mathrm{c}$ correspond to the high solar wind dynamic pressure regions $\mathrm{a}, \mathrm{b}$ and $\mathrm{c}$. As mentioned above, the short-period high pressure region $b$ is assumed to occur within the data gap, and there is a small time shift between the high pressure region $\mathrm{c}$ and the corresponding ion flow event. That may be because we assumed a constant time shift of $50 \mathrm{~min}$ while the solar wind velocity fluctuated (Fig. 2). The coincidence of the solar wind dynamic pressure and Cluster data suggests the possibility of the structured cusp arising from the inward and outward movements of the magnetopause with respect to Cluster, which will be 

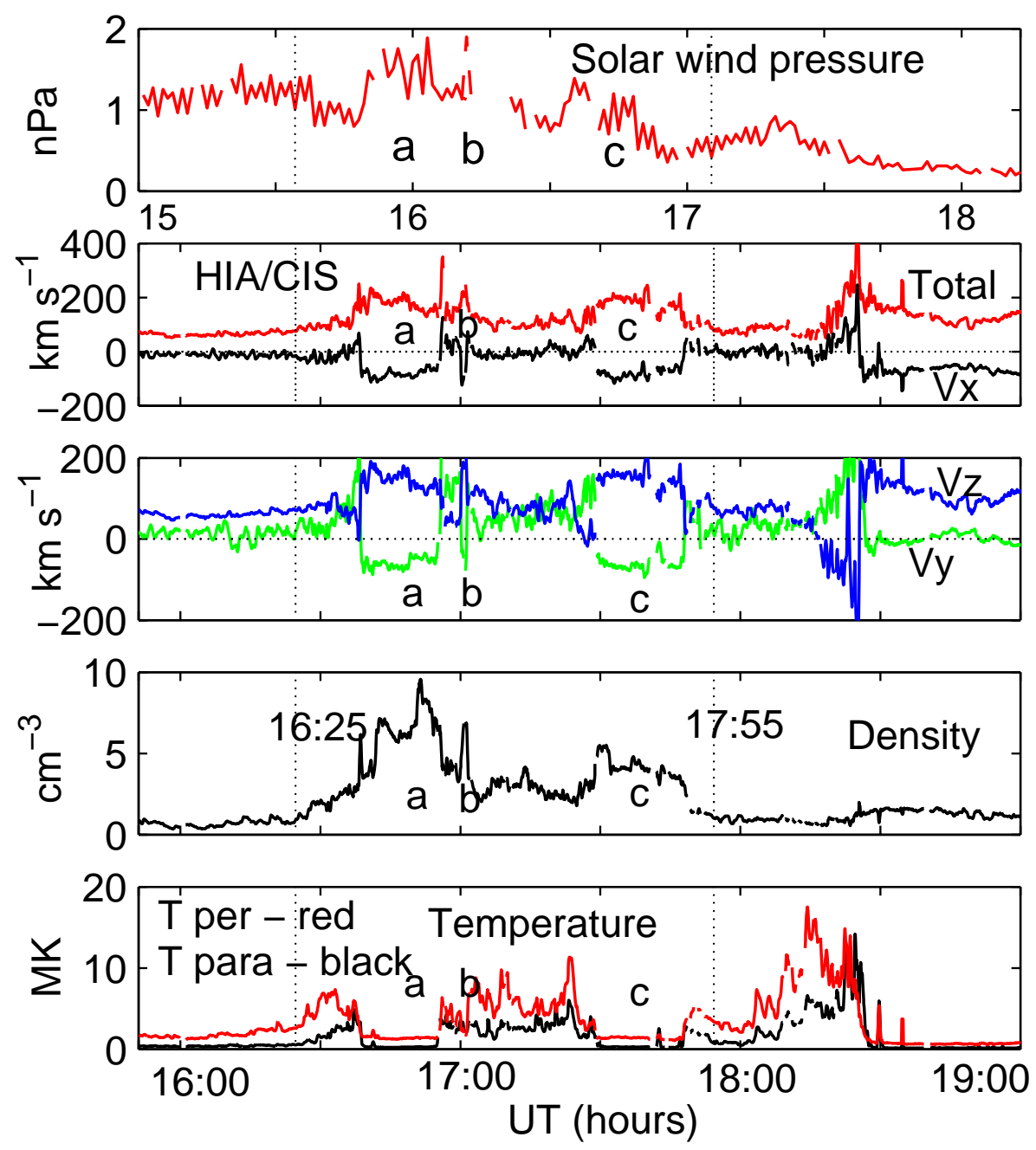

Fig. 4. The CIS data during 15:50-19:00 UT on 18 April 2002 and solar wind dynamic pressure (top panel), shifted by 50 min. The CIS data are the total ion velocity in red and its X-component $V_{x}$ in black (panel 2), $V_{y}$ and $V_{z}$ components (panel 3), ion density (panel 4), and parallel (black) and perpendicular (red) ion temperatures (panel 5) measured by HIA/CIS on Cluster SC3. The time interval (16:25-17:55 UT) between the vertical lines corresponds to the period of interest; $a, b$ and $c$ are anti-sunward ion flow events during 16:38:42-16:56:10 UT, 17:00:10-17:01:40 UT, and 17:29:15-17:48:28 UT.

discussed below. The local dynamic pressure at Cluster calculated from the CIS data ( $V_{x}$ and ion density), though less than $0.2 \mathrm{nPa}$, is found to increase over 10 times at the start of all three ion flow events (a, b, and c).

Figure 5a shows the magnetic field components $\left(B_{x}, B_{y}\right.$ and $B_{z}$ ) measured by FGM on SC3. The field components, like the ion velocity components (Fig. 4), undergo sharp changes at the boundaries of the anti-sunward ion flow events, which are numbered 1 to 6 in $B_{y}$ (Fig. 5a). A comparison of the field components shows that the total field is dominated by $B_{z}$.

The duskward electric field measured by EFW on $\mathrm{SC} 3$ is shown in Fig. 5b (bottom panel). The field is perpendicular to the GSE X axis and is in the spin plane of the spacecraft. Since the spin plane is close to the ecliptic plane, the duskward direction is close to the GSE Y axis. The electric field (Fig. 5b) shows three eastward regions a, b and c, which could be caused by the ion velocity events (Fig. 3) through $\boldsymbol{V} \times \boldsymbol{B}$ effect, in this case through $\boldsymbol{V}_{x} \times \boldsymbol{B}_{z}$ effect. On the other hand, if the electric field changes are initiated first (possibly through space charge separation), then that can act as the source for the ion velocity changes. The bottom panel of Fig. 5b compares the measured (black) and calculated (red) $V_{x}$ component of the ion velocity; the velocities, including the velocity spikes, agree well. However, the calculated velocity $\left(\boldsymbol{E}_{y} \times \boldsymbol{B}_{z}\right)$ is not shown after 18:15 UT as the velocity undergoes abnormally large fluctuations due to the field $\left(B_{z}\right.$, Fig. 5a) fluctuating around zero.

Figure 6 shows the magnetic and electric wave intensities measured by STAFF and WHISPER on SC3. As shown, 

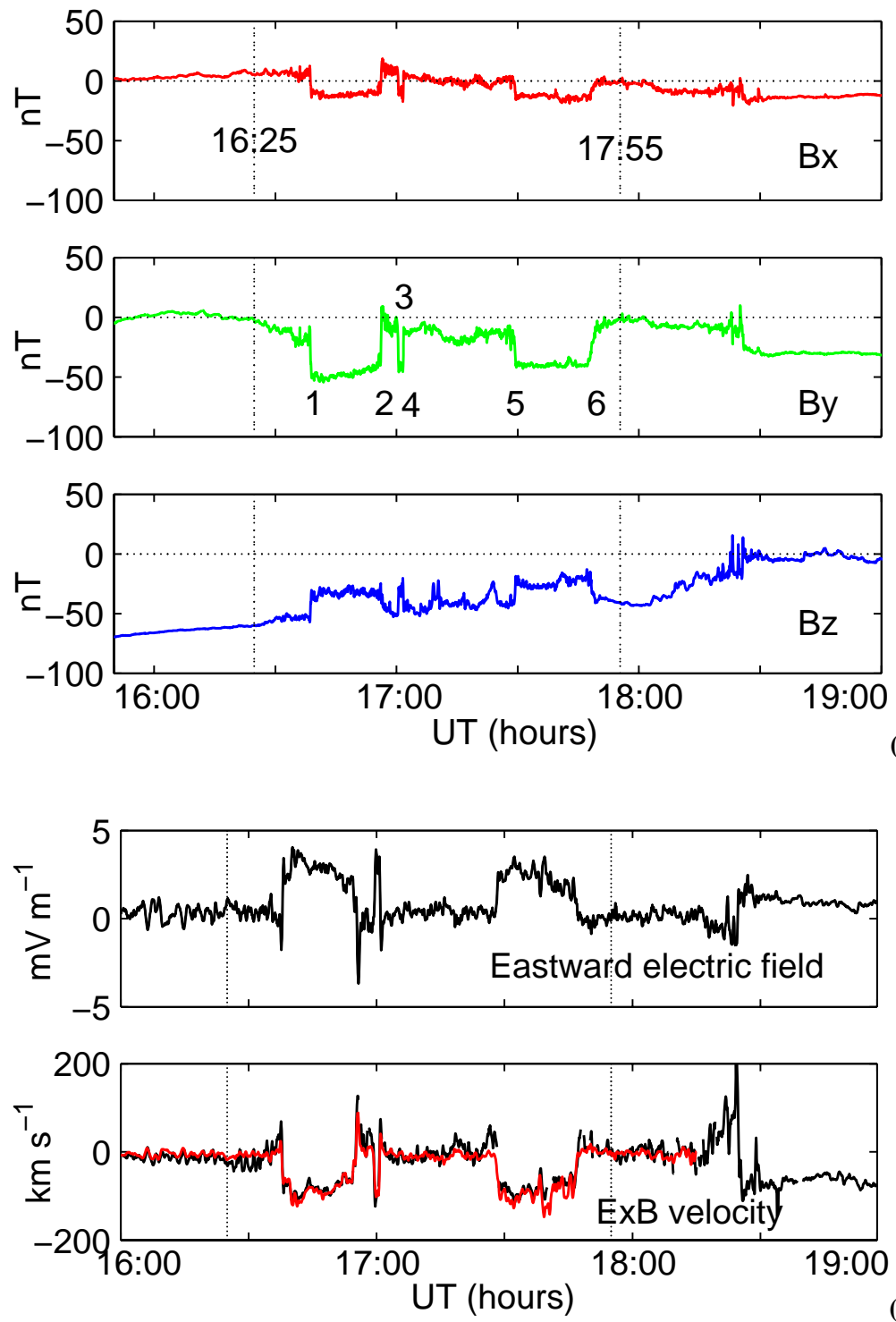

Fig. 5. (a) Magnetic field components $B_{x}, B_{y}$ and $B_{z}$ (bottom panels) from FGM on Cluster SC3 during 15:50-19:00 UT on 18 April 2002. The cusp crossing period (16:25-17:55 UT) is marked between the vertical lines. The inward and outward boundaries of the anti-sunward ion flow events ( $\mathrm{a}, \mathrm{b}$ and $\mathrm{c}$ ) are numbered 1 to 6 in $B_{y}$. (b): Eastward (positive) electric field measured by EFW on Cluster SC3 during 16:00-19:00 UT on 18 April 2002 (top). The bottom panel compares the calculated (red) and measured (black) ion velocity $V_{x}$. The velocity is calculated ( $\boldsymbol{V}_{x}=\boldsymbol{E}_{y} \times \boldsymbol{B}_{z}$ ) using the electric field $\boldsymbol{E}_{y}$ in the top and magnetic field $\boldsymbol{B}_{z}$ in Fig. 5a.

strong magnetic and electric waves are generated in the cusp region as noticed in case studies (e.g. Grison et al., 2005) and statistical studies (e.g. Cargill et al., 2005). At around each magnetic field rotations (numbered 1 to 6 in Fig. 5a), the magnetic wave power generally maximises in a way that is known to occur at magnetopause crossings (Rezau et al., 2001). The wave intensities in the medium frequency ranges noted in the figure alone are shown. The low and high frequency waves are also found to undergo similar variations.

\subsection{Multi-point observations}

Figure 7 shows the $\mathrm{X}$-component of the ion velocity (top panel) and ion density (middle panel) available from the HIA/CIS instruments in satellites SC1 (black) and SC3 (green), and electron density from the WHISPER instruments in all satellites (bottom panel). As shown, the ion velocities and ion densities from the two satellites are equal except for very small difference in densities in the ion flow events $(a, b$, and $c)$. The electron densities from different satellites also show some differences. The ion and electron 

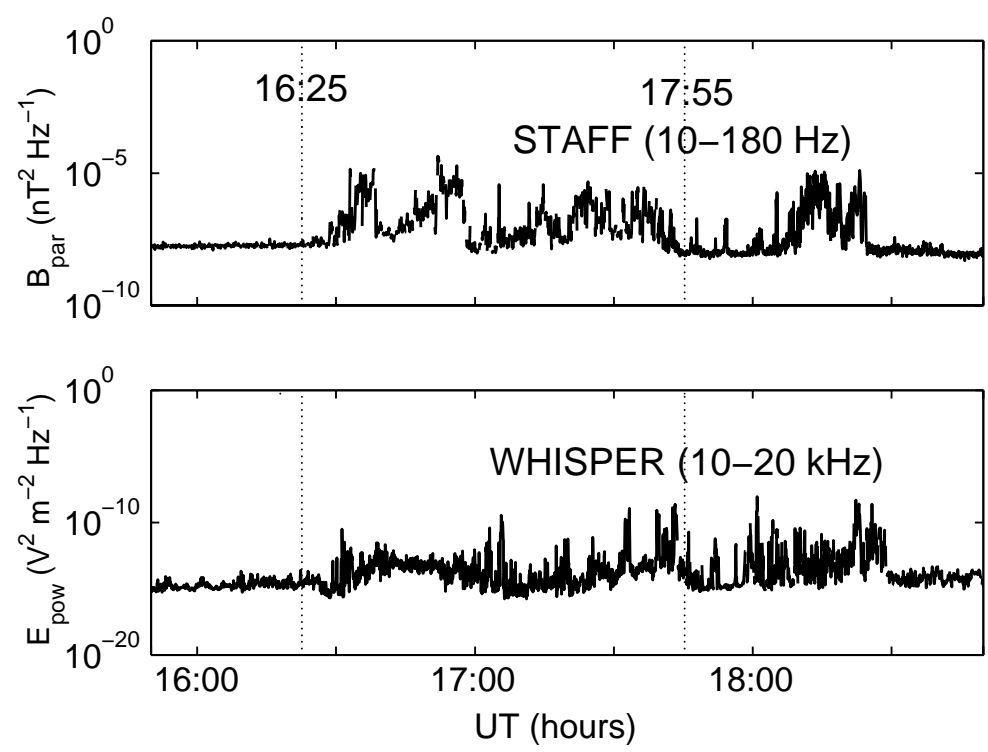

Fig. 6. Intensity of the magnetic waves $(10-180 \mathrm{~Hz})$ parallel to the magnetic field measured by STAFF (top) and intensity of the electric waves (10-20 kHz) measured by WHISPER (bottom) on Cluster SC3 during 15:50-18:50 UT on 18 April 2002.
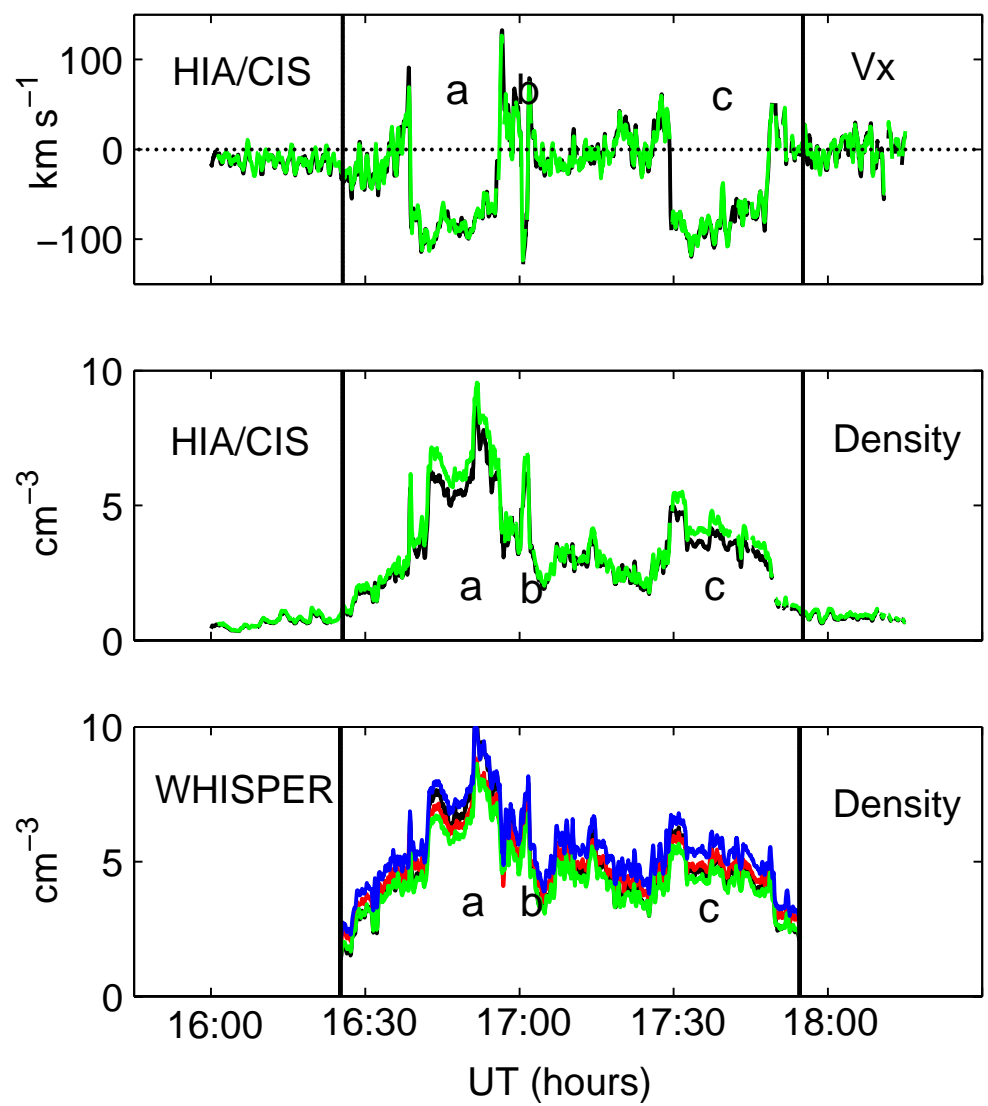

Fig. 7. X-component of the ion velocity (top panel) and ion density (middle panel) from HIA/CIS on Cluster SC1 (black) and SC3 (green), and electron density (bottom panel) from WHISPER on SC1 (black), SC2 (red), SC3(green) and SC4 (blue) during 16:00-18:15 UT on 18 April 2002. The time interval (16:25-17:55 UT) between the vertical lines corresponds to the period of interest; a, b and c are antisunward ion flow events. 
densities (middle and bottom panels) exhibit similar features and agree reasonably well in the anti-sunward ion flow events. However, outside the events, the ion densities are lower than the electron densities. That may be due to the presence of cold ions hidden to the CIS instruments when the ion flow velocity is low (Sauvaud et al., 2001).

As discussed above (Fig. 4), the anti-sunward ion flow events correspond to the high pressure regions in the solar wind, which suggests the possibility of the structured cusp arising from the inward and outward movements of the magnetopause with respect to Cluster. The possibility is illustrated in Fig. 8 which contains the locations of the magnetopause and Cluster at certain times of interest, obtained using the magnetopause model of Shue et al. (1998). The model assumes that the magnetopause is rigid and responds instantaneously to the changes in the solar wind pressure and IMF $B_{z}$.

The magnetopause and Cluster locations in Fig. 8 correspond to the ACE and Cluster times noted in the inset, with Cluster times in brackets. The black, green and cyan curves and respective circles correspond to three typical ACE times (15:45 UT, 16:08 UT and 16:30 UT) when the solar wind dynamic pressure is low, which also correspond to the Cluster times before the first, second and third ion flow events (Fig. 4). As shown by these curves and circles, the Cluster is inside the magnetopause (outer cusp) when the solar wind pressure is low. When the pressure is increased, Cluster is at or outside the magnetopause (or in the magnetosheath) as shown by the red, blue and magenta curves and respective stars (Fig. 8). Hence Cluster measured the plasma, fields and waves (Figs. 3-7) in the outer cusp when the solar wind dynamic pressure was decreasing and in the magnetosheath when the pressure was increasing, and the later corresponds to the anti-sunward ion flow events. Note that the red and blue stars and green circle in Fig. 8 touch.

The first increase in the solar wind pressure (Fig. 4, top panel) has compressed the magnetopause by about $1.5 R_{E}$, and Cluster is found to touch the magnetopause about five minutes later (compare the black and red curves, and red curve and red star in Fig. 8). However, the Cluster data (Figs. 3-7) show that Cluster entered the magnetosheath (first ion flow event) at the time corresponding to the beginning of the first increase in the solar wind pressure. The difference may be due to the uncertainties of the model (Shue et al., 1998) and time resolution of solar wind (64 s). Other parameters like solar wind azimuthal flow or IMF components (Fig. 2) do not show any change at the beginning of the first ion flow event. At the end of the first high pressure, the magnetopause retreats by about $0.75 R_{E}$ and Cluster happens to be inside the magnetopause (outer cusp) again as shown by the green curve and circle (Fig. 8). The above process is repeated at the second and third increases in the solar wind pressure; Cluster happens to be in the magnetosheath when the pressure is high (compare the blue and magenta curves and stars) and in the magnetosphere (outer cusp) when the

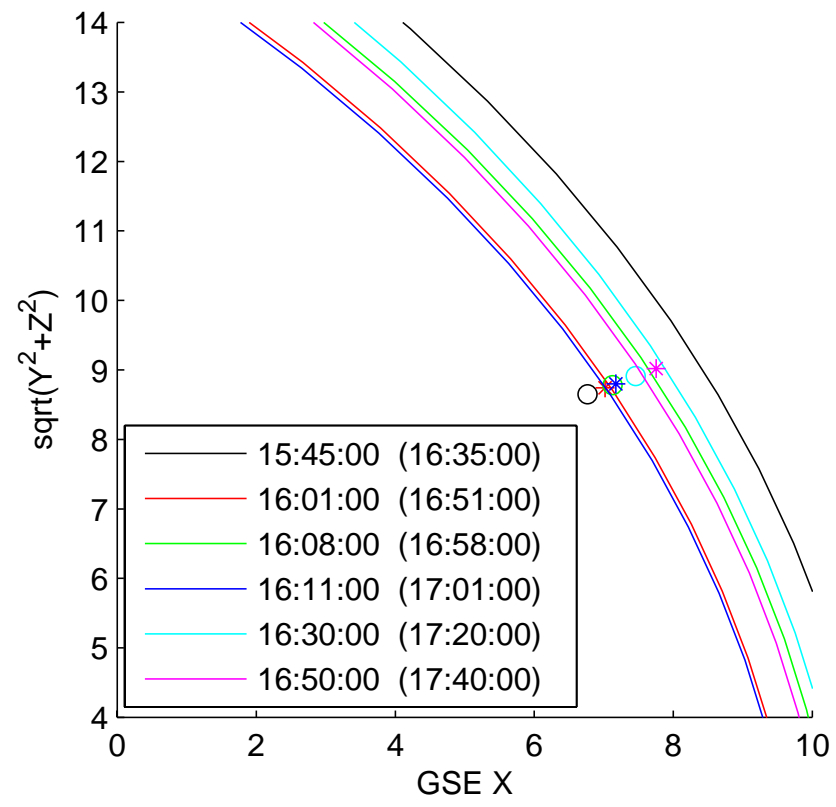

Fig. 8. Location of magnetopause obtained from the model of Shue et al. (1998) and Cluster at certain times of interest: Before the first ion flow event a (16:35 UT, black), in ion flow event a (16:51 UT, red), after ion flow event a (16:58 UT, green), in second ion flow event b (17:01 UT, blue), after ion flow event b (17:20 UT, cyan) and in third ion flow event c (17:40 UT, magenta). The curves show magnetopause locations at ACE times and symbols (stars for times in ion flow events and circles for times outside the events) show Cluster locations at Cluster times (in brackets). Cluster and MP positions are shown in same colour.

pressure is low (cyan curve and circle). The sharpness of the ion flow boundaries (Fig. 5a) also agree with the rapid response of the magnetopause to the changes in the solar wind pressure (Shue et al., 1998).

\subsection{Ion Flow Boundaries}

The observations also show that the four spacecraft cross the sharp inward boundaries (Fig. 5a) of the ion flow events in one time sequence, and their outward boundaries in the reverse time sequence. That is found to be clearer in the magnetic field and ion velocity data contained in Figs. 9 and 10 that show 2 min of the data centred around the boundaries. Figure 9a shows the crossing of the first inward boundary in all magnetic field components $\left(B_{x}, B_{y}\right.$ and $\left.B_{z}\right)$. The boundary is crossed in sequence by the satellites SC4, SC1, SC2 and SC3. Figure $9 \mathrm{~b}$ shows the crossing of all the inward and outward boundaries, the $B_{y}$ component alone is shown. As shown, all the inward boundaries (1,3 and 5) are crossed in the same sequence (SC4, SC1, SC2 and $\mathrm{SC} 3$ ) and outward boundaries ( 2 and 4 ) are crossed in the reverse sequence (SC3, SC2, SC1 and SC4). Figure 10 is similar to Fig. 9b but for the ion velocity. As with the magnetic field (Fig. 9b), all the inward boundaries (1, 3 and 5) in ion velocity (Fig. 10) 

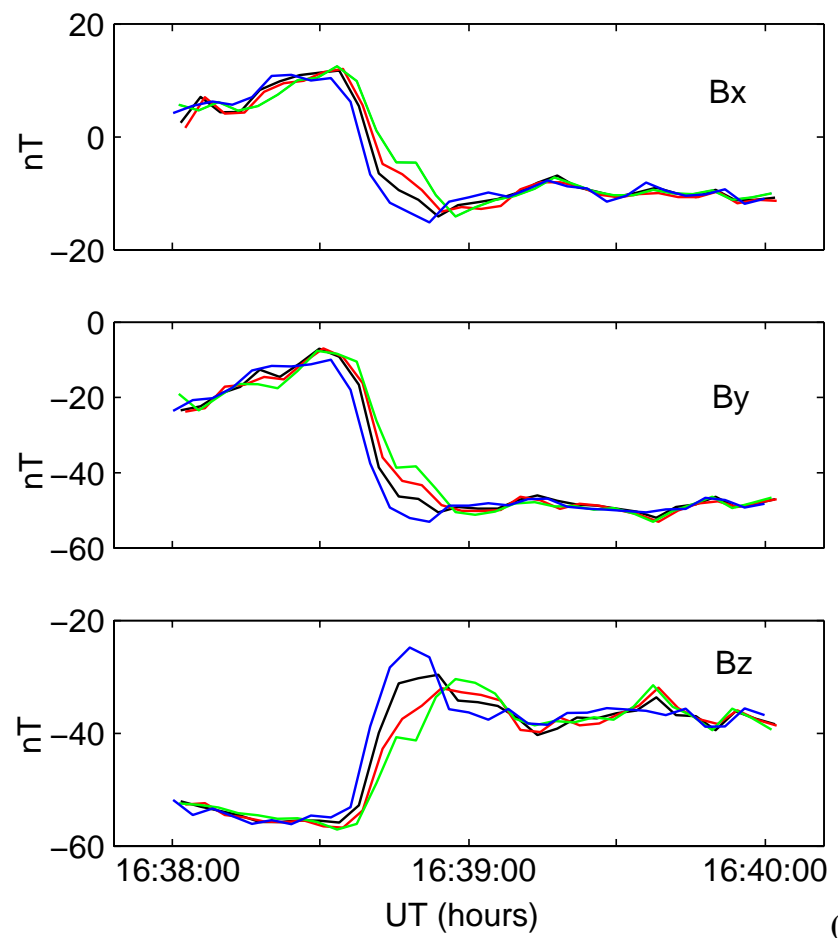

(a)
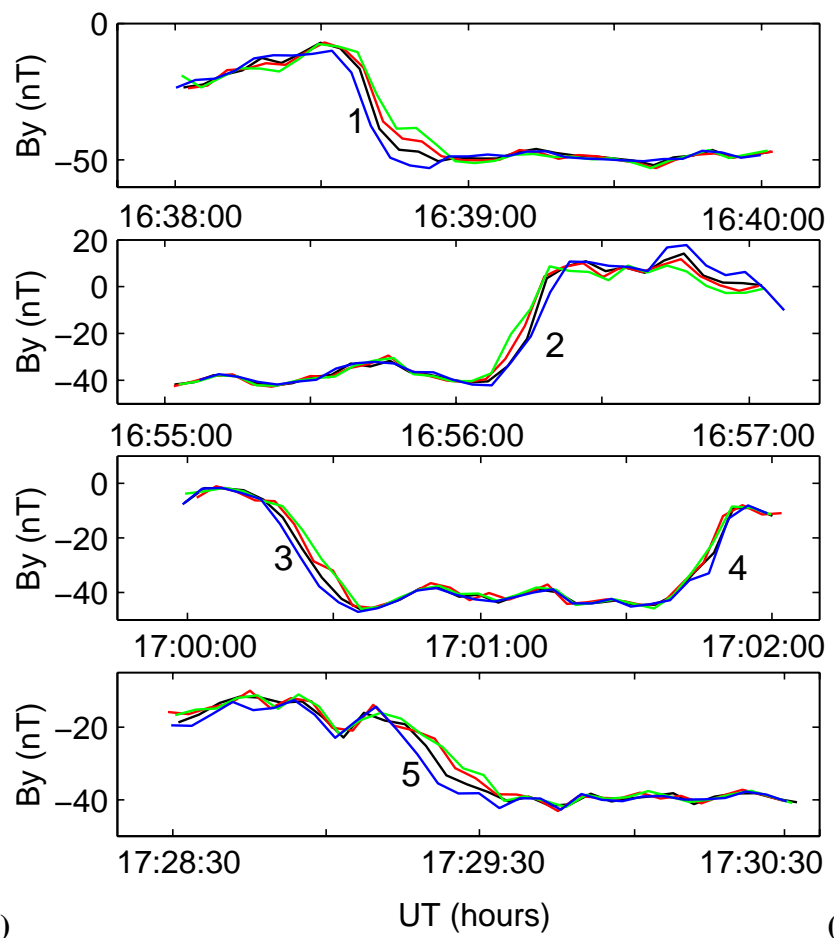

(b)

Fig. 9. (a): Crossing of the inward boundary of the first anti-sunward ion flow event at around 16:38:40 UT in sequence by Cluster SC4 (blue), SC1 (black), SC2 (red) and SC3 (green). Two minutes of the $B_{x}, B_{y}$ and $B_{z}$ data from FGM during 16:38:00-16:40:00 UT are shown. (b): Crossing of the inward boundaries (1, 3 and 5) of the anti-sunward ion flow events in sequence by SC4 (blue), SC1 (black), SC2 (red) and SC3 (green), and crossing of the outward boundaries (2 and 4) in the reverse sequence by SC3, SC2, SC1 and SC4. Two minutes of $B y$ data from FGM centred around 16:39:00 UT (crossing 1), 16:56:00 UT (crossing 2), 17:01:00 UT (crossings 3 and 4), and 17:29:30 UT (crossing 5) are shown. The outward boundary (6) of the last event is not shown for being comparatively slow.

are crossed in the same sequence (SC4, $\mathrm{SC} 1$ and $\mathrm{SC} 3$ ) and all the outward boundaries ( 2 and 4 ) are crossed in the reverse sequence; no CIS data is available from SC2.

The observed sequence of crossings of the ion flow boundaries can also be understood in terms of the inward and outward movements of the magnetopause with respect to Cluster, discussed above. As shown by the spacecraft configuration (inset in Fig. 10, and Fig. 1), the pairs of spacecraft $\mathrm{SC} 4-\mathrm{SC} 1$ and $\mathrm{SC} 2-\mathrm{SC} 3$ are oriented roughly parallel to the magnetopause, the pair SC4-SC1 is closer to the magnetopause, and spacecraft SC4 leads along the orbit; the spacecraft separation is very much enlarged. With this configuration, as the magnetopause moves inward (due to increased pressure), it could cross the satellite pair SC4-SC1 first and SC2-SC3 later as observed. Later, when the magnetopause moves outward (due to decreased pressure), it could cross the satellite pairs in the reverse sequence as observed.

Zong et al. (2004), who presented the RAPID data during this Cusp event, discussed the event in terms of the changes in the solar wind azimuthal flow and IMF $B_{y} / B_{z}$. They considered three low density regions (triple cusp) among two high density regions (ion flow events). Following their discussion (Zong et al., 2004), the spacecraft, after crossing the first low density region (first cusp), were flying through the ion flow (high density) region. At that time (around 17:05 UT, Cluster time), the solar wind azimuthal flow changed from about $10 \mathrm{~km} \mathrm{~s}^{-1}$ to $-50 \mathrm{~km} \mathrm{~s}^{-1}$. The wind velocity pulse in the -Y direction would cause a dynamic pulse to push the magnetosphere (and the ion flow region) dawnward and hence the spacecraft entered the low density region for the second time (second cusp). While the azimuthal flow remained high, IMF $B_{y}$ and $B_{z}$ showed sharp changes; IMF $B_{y}$ jumped from $-8.0 \mathrm{nT}$ to $-12.0 \mathrm{nT}$ and IMF $B_{z}$ changed from $-9.0 \mathrm{nT}$ to $-6.5 \mathrm{nT}$ (Zong et al., 2004). Since the enhanced IMF $B_{y}$ was about twice as large as $B_{z}$, the reconnection site shifted to a high latitude region (dawnside, antiparallel). Hence the spacecraft again entered the ion flow (high density) region. The dawnside field would then be eroded, moving the dawnside magnetosphere earthward and the cusp to lower latitudes. That caused the spacecraft to enter the low density region for the third time (third cusp). 
Though Zong et al. (2004) also considered the cusp event as alternate regions of cusp and magnetosheath, their discussion seems to be inadequate to explain the observations. For example, "the starting of the first ion flow event (high density) is not discussed (seems to have assumed as a natural entry of Cluster into the magnetosheath), second shortlived ion flow event is not considered, explanation for the starting of the next (second in Zong et al.) ion flow event does not hold because IMF $B_{y}$ is less negative than IMF $B_{z}$ (present Fig. 2, IMF in GSM), erosion of the dawnside field needed for the low density region (third cusp) to return again to spacecraft is not clear, cusp is considered to extend to the end of the solar wind azimuthal flow (18:28 UT, Cluster time) though the plasma characteristics become different after about 17:55 UT, and sequence of crossings of the ion flow boundaries does not agree with the lateral (or longitudinal) back and forth movements of the magnetosphere with respect to Cluster".

Spatial effects such as twisted magnetic field lines, with low and high density plasma among them, can occur during $B_{y}$ dominant IMF (Maynard et al., 2001; Wing et al., 2001). However, in the present case, IMF $B_{y}$ is less than IMF $B_{z}$ and IMF has shown only one change during the cusp crossing (Fig. 2). Hence, IMF undergoing complicated twisting, with four low density and three high density plasma regions among them, seems very unlikely. In short, the structured cusp, with three anti-sunward ion flow events, is a temporal feature that arises due to three inward and outward movements of the magnetopause by about $1.5 R_{E}$ while Cluster crossed outward through the cusp (Fig. 8). The magnetopause moved due to the changes in the solar wind dynamic pressure caused mainly by the changes in the solar wind density (Fig. 2).

\section{Summary}

Cluster observations of an outer magnetospheric cusp structured with three anti-sunward ion flow events have been presented using the data from the FGM, CIS, PEACE, EFW, STAFF and WHISPER instruments. The four Cluster spacecraft crossed through the northern cusp during 16:2517:55 UT on 18 April 2002 when a moderate geomagnetic storm was in progress, solar wind dynamic pressure was rather low $(<2 \mathrm{nPa})$, and IMF $B_{z}$ was more negative than IMF $B_{y}$. The satellite entry in the cusp is identified by drop in total magnetic field, increase in high energy ion and electron fluxes, appearance of magnetosheath like $(100 \mathrm{eV})$ electron flux, drop in low energy $(<10 \mathrm{eV})$ electron flux, and starting of high intensity magnetic and electric waves. The ion density and temperature in the cusp are anti-correlated, and ion temperature exhibits strong anisotropy.

The three anti-sunward ion flow events are found to have durations of $\approx 1.5,17.5$ and $19.0 \mathrm{~min}$, with bulk plasma flow roughly parallel to the magnetopause surface. The ion and

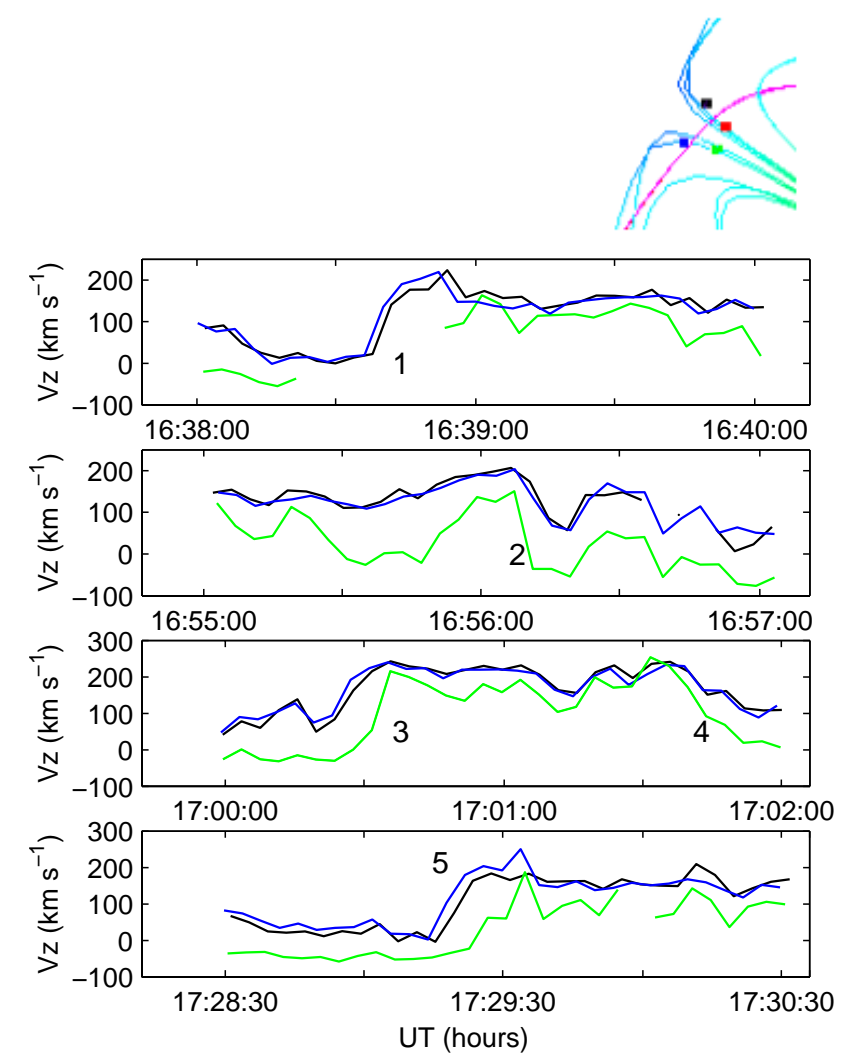

Fig. 10. Crossing of the inward boundaries (1,3 and 5) of the anti-sunward ion flow velocity in sequence by SC4 (blue), SC1 (black) and SC3 (green), and crossing of the outward boundaries ( 2 and 4 ) in the reverse sequence by SC3, SC1 and SC4. Two minutes of $V_{z}$ data from CIS centred around 16:39:00 UT (crossing 1), 16:56:00 UT (crossing 2), 17:01:00 UT (crossings 3 and 4) and 17:29:30 UT (crossing 5) are shown; no data from CIS in SC2. The outward boundary (6) of the last event is not shown for being comparatively slow. The picture in the right top shows the spacecraft configuration (expanded many times) in the cusp.

electron densities within the events are greater than those outside. The zonal electric field in the ion flow events turns eastward as expected from $\boldsymbol{V} \times \boldsymbol{B}$ effect. The sharp inward boundaries of the ion flow events cross the four spacecraft in one time sequence, and the outward boundaries of the events cross the spacecraft in the reverse time sequence. The observations studied using magnetosphere and magnetopause models suggest that the structured cusp is a temporal feature that arises due to three inward and outward movements of the magnetopause by about $1.5 R_{E}$ so that Cluster, while crossing through the cusp, happened to be in the magnetosheath (ion flow event) and cusp alternately. The magnetopause moved due to the changes in the solar wind dynamic pressure by up to $100 \%$ caused mainly by the changes in the solar wind density. 
Acknowledgements. The work at Sheffield is supported by PPARC (UK) grant No. PPA/G/S/1999/00705. We thank the Cluster instrument teams for the data used, one of the referees for useful comments, and acknowledge the use of ACE data from the Magnetic Field Experiment (MAG: P. I. N. Ness) and SWEPAM experiment (P.I. D. McComas).

Topical Editor T. Pulkkinen thanks two referees for their help in evaluating this paper.

\section{References}

Balogh, A., Carr, C. M., Acuña, M. H., et al.: The Cluster magnetic field investigation: overview of in-flight performance and initial results, Ann. Geophys., 19, 1207-1217, 2001.

Bosqued J.-M., Phan, T. D., Dandouras, I., et al.: Cluster observations of the high latitude magnetopause and cusp: initial results from the CIS ion instruments, Ann. Geophys., 19, 1545-1566, 2001.

Cargill, P. J., Dunlop, M. W., Balogh, A., and the FGM team: First Cluster results of the magnetic field structure of the mid and high altitude cusps, Ann. Geophys., 19, 1533-1544, 2001.

Cargill, P. J., Lavraud, B., Owen, C. J., Grison, B., Dunlop, M. W., Cornilleau-Wehrlin, N., Escoubet, C. P., Paschmann, G., Phan, T. D., Rezeau, L., Bogdanova, Y., and Nykyri, K.: Cluster at the magnetospheric cusps, Space Sci. Rev., 116, 321-366, 2005.

Chapman, S. and Ferraro, V. C.: A new theory of magnetic storms, Nature, 126, 129-130, 1930.

Chen, S. H., Boardsen, S. A., Fung, S. F., Green, R. L., Kessel, R. L., Tan, L. C., Eastman, T. E., and Craven, J. D.: Exterior and interior polar cusps: Observations from Hawkeye, J. Geophys. Res., 102, 11 335-11 347, 1997.

Cornilleau-Wehrlin, N., Chanteur, G., Perraut, S., et al.: First results obtained by the Cluster STAFF experiment, Ann. Geophys., 21, 437-456, 2003.

Decreau, P. M. E., Fergeau, P., Krasnoselskikh, V., et al.: Early results from the Whisper instrument on Cluster: an overview, Ann. Geophys., 19, 1241-1258, 2001.

Dungey, J. W.: Interplanetary magnetic field and the auroral zones, Phys. Rev. Lett., 6, 47-48, 1961.

Dunlop, M. W., Cargill, P., Stubbs, T., and Woolliams, P.: The high altitude cusps: HEOS-2, J. Geophys. Res., 105, 27 509-27 517, 2000.

Escoubet, C. P., Fehringer, M., and Goldstein, M.: The Cluster mission, Ann. Geophys., 19, 1197-1200, 2001.

Farrell, W. M. and Van Allen, J. A.: Observations of the Earth's polar cleft at large radial distances with the Hawkeye 1 satellite, J. Geophys. Res., 95, 20 945-20 958, 1990.

Fritz, T. A., Chen, J., and Siscoe, G. L.: Energetic ions, large diamagnetic cavities and Chapman-Ferraro cusp, J. Geophys. Res., 108, 1028, doi:10.1029/2002JA009476, 2003.

Grison, B., Sahraoui, F., Lavraud, B., Chust, T., CornilleauWehrlin, N., Réme, H., Balogh, A., and Andre, M.: Waveparticle interactions in the high-altitude polar cusp; a Cluster case study, Ann. Geophys., 23, 3699-3713, 2005.

Gustafsson, G., Andre, M., Carozzi, T., et al.: First results of electric field and density observations by Cluster EFW based on initial months of operation, Ann. Geophys., 19, 1219-1240, 2001.

Gurnett, D. A., Huff, R. L., Pickett, J. S., et al.: First results from the Cluster wideband plasma wave investigation, Ann. Geophys.,
19, 1259-1272, 2001.

Haerendel., G.: Microscopic plasma processes related to reconnection, J. Atmo. Terr. Phys., 40, 343-353, 1978.

Haerendel., G., Paschmann, G., Sckopke, N., Rosenbauer, H., and Hedgecock, P. C.: The frontside boundary layer of the magnetosphere and the problem of reconnection, J. Geophys. Res., 83, 3195-3216, 1978.

Hasegawa, H., Fujimoto, M., Phan, T.-D., Réme, H., Balogh, A., Dunlop, M. W., Hashimoto, C., and Tandokoro, R.: Transport of solar wind into Earth's magnetosphere through rolled-up KelvinHelmholtz vortices, Nature, 430, 755, doi:10.1038/nature02799, 2004.

Hedgecock., P. C. and Thomas, B. T., HEOS observations of the configuration of the magnetosphere, J. Geophys. Res., 41, 391403, 1975.

Heikkila, W. J. and Winningham, J. D.: Penetration of magnetosheath plasma to low altitude through the dayside magnetospheric cusp, J. Geophys. Res., 76, 883-891, 1971.

Hultqvist, B., Oieroset, M., Paschmann, G., and Treumann, R.: Plasma transfer processes at the magnetopause, Space Science Reviews, 88, 207-283, 1999.

Johnston, A. D., Alsop, C., Burges, S., et al.: PEACE: a plasma electron and current experiment, Space Science Rev., 79, 351398, 1997.

Krauklis, I., Fazakerley, A., Owen, C. J., et al.: Preliminary two point observations of the mid altitude cusp by Cluster PEACE and FGM, Ann. Geophys., 19, 1579-1588, 2001.

Lavraud, B., Fedorov, A., Budnik, E., Grigoriev, A., Cargill, P. J., Dunlop, M. W., Réme, H., Dandouras, I., and Balogh, A.: Cluster survey of the high-altitude cusp properties: a three-year statistical study, Ann. Geophys., 22, 3009-3019, 2004.

Lockwood, M. and Smith, M. F.: The variation of reconnection rate at the dayside magnetopause and cusp ion precipitation, J. Geophys. Res., 97, 14 841-14 847, 1992.

Lockwood, M. and Smith, F. M.: Low and middle altitude cusp particle signatures for general magnetopause reconnection rate variations: 1. Theory, J. Geophys. Res., 99, 8531-8553, 1994.

Maynard, N. C., Savin, S., Erickson, G. A., et al.: Observations of the magnetospheric sash and its implications relative to solarwind/magnetospheric coupling: A multi-satellite event analysis, J. Geophys. Res., 106, 6097-6122, 2001.

Merka, J., Safrankova, J., Nemecek, Z., Savin, S., and Skalsky, A.: High altitude cusp: INTERBALL observations, Adv. Space Res., $25,1425-1434,2000$.

Onsager, T. G., Scudder, J. D., Lockwood, M., and Russell, C. T.: Reconnection at the high latitude magnetopause during northward interplanetary magnetic field conditions, J. Geophys. Res., 106, 25 467-25 488, 2001.

Opgenoorth, H. J., Lockwood, M., Alcayde, D., et al.: Co-ordinated ground-based, low altitude satellite and Cluster observations on global and local scales during a transient post noon sector excursion of the magnetospheric cusp, Ann. Geophys., 19, 1367-1398, 2001.

Pitout, F., Bosqued, J. M., Alcayde, D., Denig, W. F., and Réme, H.: Observations of the cusp region under northward IMF, Ann. Geophys., 19, 1641-1653, 2001.

Réme, H., Aoustin, C., Bosqued, J. M., et al.: First multi-spacecraft ion measurements in and near the Earth's magnetosphere with the identical Cluster ion spectrometry (CIS) experiment, Ann. 
Geophys., 19, 1303-1354, 2001.

Russell, C. T. and Elphic, C.: ISEE observations of flux transfer events at the dayside magnetopause, Geophys. Res. Lett., 6, 3336, 1979.

Russell, C. T.: Polar eyes the cusp, proc. Cluster-II workshop on multi-scale / multi-point plasma measurements, London, 22-24 September 1999, ESA SP-449, 47, 2000.

Rezeau, L., Sahraoui, F., d'Humieres, E., Belmont, G., CornilleauWehrlin, N., Mellul, L., Lucek, E., Robert, P., Decreau, P., and Canu, P.: A case study of low-frequency waves at the magnetopause, Ann. Geophys., 19, 1463-1470, 2001.

Sandahl, I.: Recent cusp and cleft results from Interball, Adv. Space Res., 30, 1711-1714, 2002.

Sauvaud, J.-A., Stenuit, H., and McComas, D., et al.: Intermittent thermal plasma acceleration linked to sporadic motions of the magnetopause, first Cluster results, Ann. Geophys., 19, 15231532,2001

Savin, S., Zelenyi, L., Romanov, S., et al.: Magnetospheric-cusp interface, Ann. Geophys., 22, 183-212, 2004.

Sckopke, N., Paschmann, G., Rosenbauer, H., and Fairfield, D. H.: Influence of the interplanetary magnetic field on the occurrence and the thickness of the plasma mantle, J. Geophys. Res., 81, 2687-2691, 1976.

Shue, J.-H., Song, P., Russell, C. T., et al.: Magnetopause location under extreme solar wind conditions, J. Geophys. Res., 103, 17 691-17 700, 1998.

Skoug, R. M., Gosling, J. T., Steinberg, J. T., McComas, D. J., Smith, C. W., Ness, N. F., Hu, Q., and Burlaga, L. F.: Extremely high speed solar wind: October 29-30, 2003, J. Geophys. Res., 109, A09102, doi:10.1029/2004JA010494, 2004.

Smith, M. F. and Lockwood, M.: The Earth's magnetospheric cusps, Rev. Geophys., 34, 233-260, 1996.
Spreiter, J. R. and Summers, A. L., On conditions near the neutral points on the magnetosphere boundary, Planet. Space Sci., 15, 787-798, 1967.

Stubbs, T. J., Cargill, P. J., Lockwood, M., Grande, M., Kellett, B. J., and Perry, C. H.: Extended cusp-like regions and their dependence on the Polar orbit, seasonal variations, and interplanetary conditions, J. Geophys. Res., 109, A09210, doi:10.1029/2003JA010163, 2004.

Taylor, M. G. G. T., Fazakerley, A., Krauklis, I. C., et al.: Four point measurements of electrons using PEACE in the high altitude cusp, Ann. Geophys., 19, 1567-1578, 2001.

Tsyganenko, N. A. and Stern, D. P.: Modeling the global magnetic field of the large-scale Birkeland current systems, J. Geophys. Res., 101, 27 187-27 198, 1996.

Wing, S., Newell, P. T., and Ruohoniemi, J. M.: Double cusp: Model prediction and observational verification, J. Geophys. Res., 106, 25 571-25 593, 2001.

Yamauchi, I., Lundin, R., Norbergl, I., Sandahl, I., Eliasson, L., and Winningham, D.: Singantures of direct magnetosheath plasma injections onto closed field-line regions based on observations at mid and low latitudes, Earth's low latitude boundary layer, Geophysical Monograph, 133, American Geophysical Union, Washington D.C., 179-188, 2003.

Zelenyi, L. M., Traka, P., and Petrukovich, A. A.: INTERBALL dual probe and dual mission, Adv. Space Res., 20, 4/5, 549-552, 1997.

Zhang, H., Fritz, T. A., Zong, Q. G., and Daly, P. W.: Stagnant exterior cusp region as viewed by energetic electrons and ions: A statistical study using Cluster Research with Adaptive Particle Imaging Detectors (RAPID) data, J. Geophys. Res., 110, A05211, doi:10.1029/2004JA010562, 2005.

Zong, Q.-G., Fritz, T. A., Zhang, H., Korth, A., Daly, P. W., Dunlop, M. W., Glassmeier, K.-H., Rame, H., and Balogh, A.: Triple cusps observed by Cluster- Temporal or spatial effects?, Geophys. Res. Lett., L09810, doi:10.1029/2003GL019128, 2004. 